\title{
Preparation and characterization of the sol-gel silica containing ionic liquids as a potential adsorbent for the removal of chromium (vi) ions from aqueous solutions
}

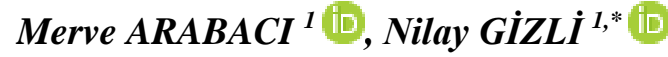 \\ ${ }^{1}$ Ege University, Faculty of EngineeringDepartment of Chemical Engineering, 35100, Bornova/ İzmir / TURKEY
}

\begin{abstract}
In this study ionic liquid mediated sol-gel silica adsorbents were prepared and characterized in order to investigate the sorption performances for the removal of $\mathrm{Cr}$ (VI) ions from aqueous solutions. High extracting ability of ILs was combined with the surface properties of silica substances by confining ILs in porous matrices. Commercial (Aliquat $336^{\circledR}$ and

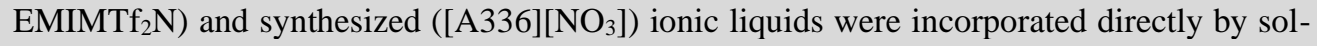
gel process. Silica based adsorbents were being initiated with silica precursor (TEOS), water, alcohol and ionic liquid hydrolysis in the presence of an acid catalyst then completed with a condensation reaction. Chemical and morphological characterizations of prepared adsorbents have been investigated by FTIR, SEM and BET analysis. The materials exhibited average pore diameter of $2 \mathrm{~nm}$, pore volume of $0.3 \mathrm{~cm}^{3} / \mathrm{g}$ and BET surface area of $300-600 \mathrm{~m}^{2} / \mathrm{g}$. The sorption behaviors of adsorbents have been investigated by using a series of batch sorption studies. $\mathrm{Cr}(\mathrm{VI})$ sorption percentages of the adsorbents were enhanced by containing ILs up to $99 \%$ with the adsorption capacity of $31.74 \mathrm{mg} / \mathrm{g}$. It can be concluded that sorption of $\mathrm{Cr}(\mathrm{VI})$ ions from aqueous solution by sol-gel silica based adsorbents containing Aliquat 336 takes place favorably and these type of adsorbents are promising agents in the adsorption processes.
\end{abstract}

\section{Introduction}

Chromium has a wide range of industrial application area such as; metal plating, leather tanning, pigment and coating industries [1]. Chromium in aqueous solutions exists in a range of oxidation state from -2 to +6. $\mathrm{Cr}(\mathrm{VI})$ exhibits toxic effects for living organisms, therefore the allowable limit is kept at low concentrations. World Health Organization (WHO) has set this limit as $0.05 \mathrm{mg} / \mathrm{L}$ for the drinking waters [2]. For that reason it is very important to develop a process for selective removal of $\mathrm{Cr}(\mathrm{VI})$ ions from aqueous solutions.

Removal and extraction of dissolved heavy metal ions from aqueous media are generally accomplished by several methods including chemical precipitation, ion exchange, adsorption [3-6], membrane filtration [7], coagulation, flocculation, flotation, and electrochemical methods [8-10]. Among all these methods, adsorption is considered as the effective technique for the removal of heavy metals from aqueous solution because of advantages like the low

\author{
Article info \\ History: \\ Received: 29.11.2017 \\ Accepted: 04.09.2019 \\ Keywords: \\ Sol-gel, \\ Silica adsorbents, \\ Ionic liquid, \\ Adsorption.
}

cost, availability, profitability, ease of operation and efficiency $[11,12]$. In general, the efficiency of the adsorption depends on many factors, including the surface area, pore size and distribution of it, as well as the surface chemistry of the adsorbents. The sorbents with a high specific surface area as a result of the porous character are generally needed for high adsorption efficiency [13].

Ionic liquids (ILs) are organic salts which have liquid form at room temperature. Because of this, they are recognized as Room Temperature Ionic Liquids (RTILs). The large number of possible ILs structures and their unique properties such as high thermal stability, non-flammability, negligible vapor pressure make them feasible to consider them as an opportunity to contribute to greenness in the various field [14]. In addition, ILs have adjustable hydrophobicity, polarity and selectivity compared with organic solvents when used for extraction [13, 15]. ILs can be used as metal extraction reagent for separation of metal ions [16, 17]. There are many advantages of ILs in separation processes such as high separation efficiency and high selectivity. However, 
some drawbacks of ILs are found in some liquidliquid separation processes, such as large amount used, high viscosity leading unfavorably to dissolve and diffuse, difficulties of separation and recovery, and the low interface area [18]. To overcome these shortcomings, ILs can be incorporated onto highly porous solid supports in many different ways, such as simple impregnation, grafting, polymerization, solgel method and encapsulation [19]. Among these, solgel method has an incredible attention because of the advantages such as; (i) easy and inexpensive; (ii) functional groups are readily anchored on the substrate; and (iii) it can be used for the deposition of substrates that have complex surfaces or large surface areas [20]. In sol-gel applications, it is reported that ILs have served as solvents [21, 22], pore templates [23, 24], drying control agent [25] and catalyst [26]. Zhang et al., synthesized silica gel materials with various RTIL as template and concluded that the increasing in alkyl chain length of imidazolium cation resulted in the increase of pore size of the silica materials [27]. The properties of ILs can be significantly changed with the various combination of cation and anion. Thus, the diversity of the selected ILs as the template in sol-gel synthesis can have important effect on the properties of the obtained porous materials [28].

In this study, Ionic Liquid (IL) mediated sol-gel silica adsorbents were prepared and used for the removal of $\mathrm{Cr}(\mathrm{VI})$ ions from aqueous solution. Three different types of ILs such as Aliquat $336^{\circledR}$, EMIMTf ${ }_{2} \mathrm{~N}$ and $[\mathrm{A} 336]\left[\mathrm{NO}_{3}\right]$ were incorporated onto silica adsorbents by following the one-step sol-gel process. Physicochemical and morphological characterizations of prepared adsorbents have been investigated by Fourier Transform Infrared Spectroscopy (FTIR) Scanning Electron Microscopy (SEM), Brunauer Emmett Teller (BET) analysis. In addition, thermal behaviors of prepared adsorbents were also characterized by Thermogravimetric Analysis (TGA). The sorption behaviors of adsorbents were investigated by a series of batch sorption experiments. Effect of the type of ILs on the adsorption performance was investigated as well as sorption percentages.

\section{Materials and Methods}

\subsection{Materials}

In this study, tricaprylylmethylammonium chloride (trade name Aliquat 336®, $(\mathrm{C} 8 \mathrm{H} 17) 3 \mathrm{CH} 3 \mathrm{NCl}), 1-$ Ethyl 3-methylimidazolium bis(trifluoromethylsulfony) imide [EMIMTf2N] and tricapryl methyl ammonium nitrate [A336][NO3] were used as ionic liquids. [A336][Cl] and EMIMTf2N were obtained from Sigma Aldrich, [A336][NO3] was synthesized by anion metathesis reaction. Tetraethyl ortosilicate with the chemical formula of $\mathrm{Si}(\mathrm{OC} 2 \mathrm{H} 5) 4$ (TEOS) was used as a precursor for obtaining $\mathrm{SiO} 2$ matrix. Required concentration of chromium solution was prepared by using potassium dichromate salt, $\mathrm{K} 2 \mathrm{Cr} 2 \mathrm{O} 7$. Also, $0.1 \mathrm{M}$ of $\mathrm{HCl}$ and $0.1 \mathrm{M}$ of $\mathrm{NaOH}$ solutions were used to adjust the $\mathrm{pH}$ of the solution. Chemical structures of commercial ionic liquids are shown in Figure 1.

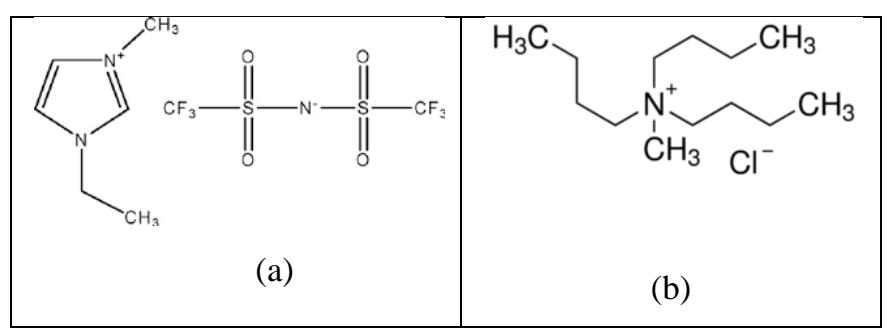

Figure 1. Chemical structures of commercial ionic liquids a) EMIMTf $_{2} \mathrm{~N}$ b) Aliquat $336^{\circledR}$.

\subsection{Synthesis of the task specific ionic liquid}

A336 [NO3] (task specific IL) was synthesized by anion metathesis reaction of Aliquat $336{ }^{\circledR}$ with KNO3 solution. Reaction can be given as follows;

\section{$\mathrm{A} 336[\mathrm{Cl}]+\mathrm{KNO} 3 \longrightarrow \mathrm{A} 336[\mathrm{NO} 3]+\mathrm{KCl}$}

Ionic liquid (A336[Cl]) and $2 \mathrm{M}$ of $\mathrm{KNO} 3$ solutions were contacted for 1 hour by vigorous stirring. The phases were then separated by using a separating funnel followed by washing with distilled water. These steps were repeated for 4 times. Completion of the reaction was controlled by checking the $\mathrm{Cl}$ - ion content of the ionic liquid by using AgNO3 solution.

\subsection{Adsorbent preparation}

Sol-gel process was used for the preparation of sorbents based on nanoporous silica oxide matrices in whose interconnected network, ionic liquid got trapped. In this manner, $5 \mathrm{~mL}$ of TEOS as a silica precursor and $2.5 \mathrm{~mL}$ of $\mathrm{EtOH}$ were mixed in an ultrasonic media. And various amount of IL (0-14\%) were added into TEOS-EtOH solution and mixed at $40^{\circ} \mathrm{C}$ during $30 \mathrm{~min}$. Then, $2.5 \mathrm{ml}$ of aqueous $\mathrm{HCl}$ solution (37 wt \%) was added as dropwise and the solution was mixed during futher 2 hours. Then, the solution was poured into the moulds and left to dry at ambient conditions. Finally obtained products was ground into powders for the subsequent characterization and adsorption studies. Prepared 
sorbents are abbreviated according to type of $\mathrm{IL}$, as given in Table 1.

Table 1. Nomenclature of prepared silica adsorbents

\begin{tabular}{ll}
\hline ID & Ionic Liquid \\
\hline SG- & - \\
SG-A & Aliquat $336^{\circledR}$ \\
SG-TS & {$\left[\right.$ A336] $\left[\mathrm{NO}_{3}\right]$} \\
SG-IL & {$\left[\right.$ EMIMTf $\left._{2} \mathrm{~N}\right]$} \\
\hline
\end{tabular}

\subsection{Characterization}

The functional groups of the prepared adsorbents were investigated by using a Fourier Transform Infrared spectrometer (FTIR-Pelkin Elmer Spectra 100 ) in the wave number range of $650-4000 \mathrm{~cm}^{-1}$. The surface morphology of adsorbents was investigated by using Scanning Electron Microscope (SEM). The microscope was operated at an accelerating voltage of $20.00 \mathrm{kV}$. The particles were coated with a gold layer in order to make them conductive. Surface area and pore volume of silica adsorbents were analyzed by Brunauer-Emmett-Teller (BET) in Micromeritics Gemini V model. Thermal Gravimetric Analysis (TGA) was carried out using Perkin Elmer Diamond TG/DT model to investigate the thermal behavior of the silica particles.

\subsection{Batch sorption studies}

The adsorption of $\mathrm{Cr}$ (VI) ions from aqueous solutions onto the silica based adsorbents was investigated by a series of batch sorption tests to obtain the adsorption performances of adsorbents as removal percentage.

For the batch adsorption studies, solution varying concentration $(50-700 \mathrm{mg} / \mathrm{L})$ of $\mathrm{Cr}(\mathrm{VI})$ were equilibrated with $50 \mathrm{mg}$ of adsorbents by shaking at $150 \mathrm{rpm}$ using a NUVE model ST 30 water-bath shaker. After equilibration, the adsorbents were removed and the supernatants were analyzed for $\mathrm{Cr}(\mathrm{VI})$ concentration by using Atomic Absorption spectrophotometer (Perkin Elmer, Varian $10 \quad+$ ) (AAS). The percentage of $\mathrm{Cr}(\mathrm{VI})$ removal $\mathrm{R}(\%)$, was calculated by using the following expression:

$\mathrm{R}(\%)=\frac{\left(\mathrm{C}_{0}-\mathrm{C}_{\mathrm{e}}\right)}{\mathrm{C}_{0}} 100$

where $\mathrm{C}_{0}$ and $\mathrm{C}_{\mathrm{e}}$ are the initial and equilibrium concentrations (mg/L), respectively. Equilibrium concentration represents the concentration value where the adsorption isotherm reaches plateau.

The adsorption capacity of the prepared adsorbents was evaluated using the following equation:
$\mathrm{q}_{\mathrm{e}}=\frac{\left(\mathrm{C}_{0}-\mathrm{C}_{\mathrm{e}}\right) \mathrm{V}}{\mathrm{m}}$

where $\mathrm{q}_{\mathrm{e}}$ is the adsorption capacity $(\mathrm{mg} / \mathrm{g}), \mathrm{C}_{0}$ and $\mathrm{C}_{\mathrm{e}}$ are the initial and equilibrium concentrations $(\mathrm{mg} / \mathrm{L})$, respectively. $\mathrm{V}$ is the volume of $\mathrm{Cr}(\mathrm{VI})$ solution and $\mathrm{m}$ is the mass of dry adsorbent

\section{Results and Discussion}

\subsection{Characterization}

\subsubsection{Chemical characterization- FTIR analysis}

FTIR spectrums of the untreated silica, ionic liquid confined silica and bulk ionic liquids are shown in Figure 2.

In the FTIR spectra of untreated silica materials (SGØ) (Figure 2 a), typical indication of silica structure are observed with the peaks of $\mathrm{Si}-\mathrm{O}-\mathrm{Si}$ groups appeared at 1060 and $790 \mathrm{~cm}^{-1}$ wavelengths. In addition, the peak at the wavelength of $947 \mathrm{~cm}^{-1}$ is assigned to the vibration of $\mathrm{Si}-\mathrm{OH}$ which remarks the hydroxyl group of the particle surface. Another peak at $3259 \mathrm{~cm}^{-1}$ wavelength can also be attributed as the indication of unreacted $-\mathrm{OH}$ structure. At this wavelength, $-\mathrm{OH}$ peaks are decreased or disappeared with the incorporation of ionic liquid due to the replacement of hydroxyl group of silica structure with the organic group of ionic liquids.

The FTIR spectrum of [A336][Cl ] (Figure 2.c), the peaks around the position of $2923 \mathrm{~cm}^{-1}$ can be attributed to the characteristic absorption of $-\mathrm{CH} 3$ of alkyl chain and peaks at the position of 1466 and $1378 \mathrm{~cm}^{-1}$ are based on the structure of quaternary ammonium moiety of the ionic liquid. The peak located at $1465 \mathrm{~cm}^{-1}$ (Figure $2 \mathrm{~b}$ ) is pronounced functionalization of silica particles with $[\mathrm{A} 336][\mathrm{Cl}]$ type ionic liquid.

Peaks appeared at 3159 and $1574 \mathrm{~cm}^{-1}$ wavelengths (Figure $2 \mathrm{e}$ ) can be attributed as the $\mathrm{C}=\mathrm{N}$ bonds of the imidazolium ring. Also, the bands around 1067 and $795 \mathrm{~cm}^{-1}$ indicate the asymmetric and symmetric stretching of $\mathrm{Si}-\mathrm{O}-\mathrm{Si}$ vibration, respectively. These data are the important indications for the ionic liquid presence in SG-IL structure.

The peaks around the position of $2924 \mathrm{~cm}^{-1}$ can be attributed to the characteristic absorption of $-\mathrm{CH} 3$ of alkyl chain and the bands between 1467 and $1328 \mathrm{~cm}^{-}$ ${ }^{1}$ are based on the structure of quaternary ammonium moiety of the ionic liquid. The peak located at 1326 $\mathrm{cm}^{-1}$ (Figure $2 \mathrm{f}$ ) is pronounced functionalization of silica particles with [A336][NO3] type ionic liquid. 


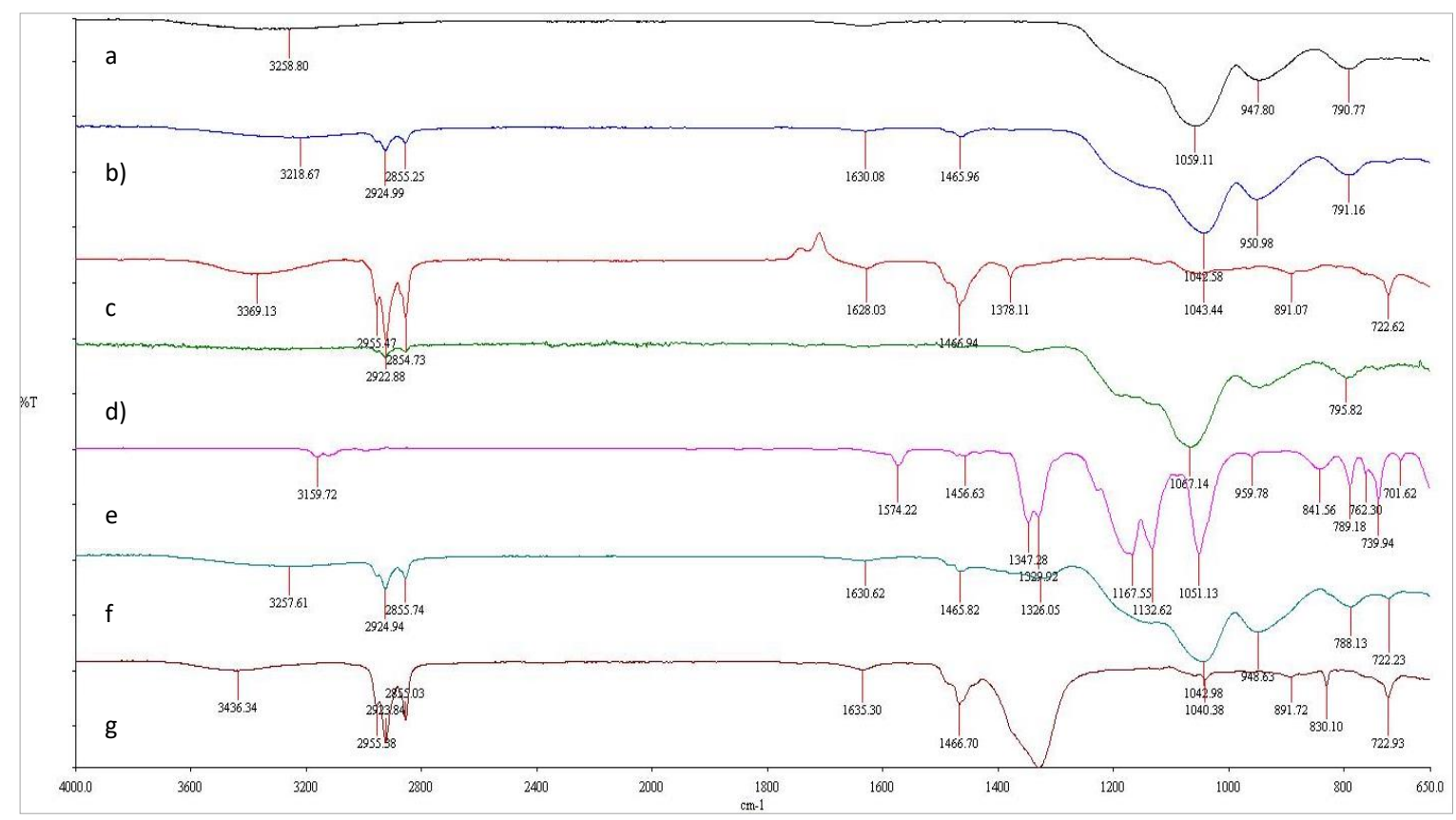

Figure 2. FTIR spectra of ionic liquid functionalized silica based adsorbents a) before functionalization (SG-Ø) b) adsorbent (SG-A) functionalized with [A336][Cl] c) ionic liquid [A336][Cl] (Aliquat 336) d) adsorbent (SGIL) functionalized with EMIMTf ${ }_{2} \mathrm{~N}$ e) ionic liquid EMIMTf $\mathrm{E}_{2} \mathrm{~N}$ f) adsorbent (SG-TS) functionalized with $[\mathrm{A} 336]\left[\mathrm{NO}_{3}\right] \mathrm{e}$ ) ionic liquid $[\mathrm{A} 336]\left[\mathrm{NO}_{3}\right]$

\subsubsection{Surface properties- BET analysis}

BET surface area $\left[\mathrm{m}^{2} / \mathrm{g}\right]$ and pore width $[\mathrm{nm}]$ values of silica based and ionic liquid functionalized silica adsorbents are shown in Table 2.

Table 2. BET analysis data of prepared adsorbents.

\begin{tabular}{|c|c|c|c|c|c|c|}
\hline \multirow[b]{2}{*}{ Adsorbents } & \multicolumn{4}{|c|}{ Surface Area $\left[\mathrm{m}^{2} / \mathrm{g}\right]$} & \multirow{2}{*}{$\begin{array}{c}\text { Pore } \\
\text { Volume } \\
{\left[\mathrm{cm}^{3} / \mathrm{g}\right]}\end{array}$} & \multirow[b]{2}{*}{$\begin{array}{c}\text { Pore Size } \\
\text { [nm] }\end{array}$} \\
\hline & BET & Langmuir & $\begin{array}{c}\text { t-Plot } \\
\text { Micropore }\end{array}$ & $\begin{array}{l}\text { t-Plot } \\
\text { External }\end{array}$ & & \\
\hline SG-Ø & 577 & 744 & 148 & 428 & 0.30 & 2.13 \\
\hline SG-IL & 299 & 402 & - & 372 & 0.23 & 3.07 \\
\hline SG-TS & 593 & 755 & - & - & 0.34 & 2.07 \\
\hline SG-A & 602 & 762 & - & - & 0.32 & 2.03 \\
\hline
\end{tabular}

As shown in Table 2. silica based adsorbents functionalized with various type of ILs were characterized to be mesoporous with average pore diameter of $2 \mathrm{~nm}$ and BET surface area in the range of $300-600 \mathrm{~m}^{2} / \mathrm{g}$. Pore volumes of SG-TS and SG-A are higher than SG (untreated) type adsorbents while average pore diameters of adsorbents containing TS and A type ionic liquids are lower than SG leading to higher surface area. On the other hand surface area of SG- $\varnothing$ adsorbents decreases with modification with IL type ionic liquids. This may be attributed that the surface area is occupied by the long alkyl chain of EMIMTf $_{2} \mathrm{~N}$ type ionic liquid.

\subsubsection{Morphological characterization- SEM analysis}

The morphological characteristics of SG-A, SG-TS and SG-IL were evaluated respectively using a Scanning Electron Microscopy (SEM) as shown in Figure 3. 


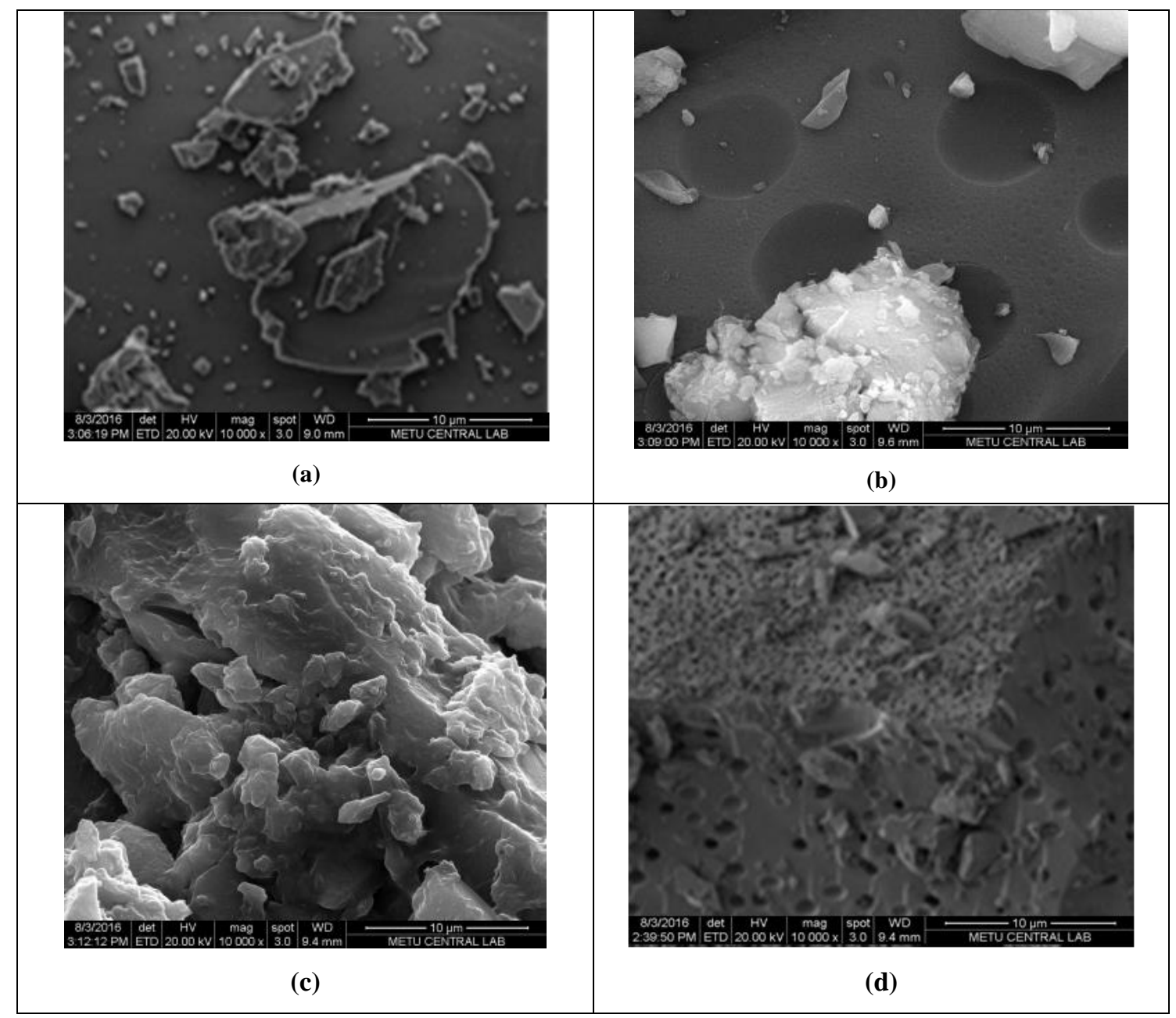

Figure 3. SEM images of prepared adsorbents with the magnification rate of 10000 a) SG- $\varnothing$ b) SG-A c) SG-TS d) SG-IL.

In the SEM images of silica materials having none IL content (SG-Ø), it is observed that, the surface area of SG has nonporous and nonhomogeneous structures. Pore structure formation is observed by presence of the ionic liquid especially Aliquat $336{ }^{\circledR},[\mathrm{A} 336][\mathrm{Cl}]$, (SG-A) and imidazolium based IL, EMIMTf ${ }_{2} \mathrm{~N}$, (SGIL). From the SEM images it can be concluded that ionic liquids acted as porogens in the preparation of silica adsorbents.

\subsubsection{Thermal behavior analysis- TGA}

Thermal stability of the bulk IL and silica based adsorbents containing various amount of ILs are shown in the Figure 4.

In TGA thermograms (Figure 4), it is clearly observed that decomposition temperature $\left(\mathrm{T}_{\mathrm{d}}\right)$ of bulk IL $\left([\mathrm{EMIM}]\left[\mathrm{Tf}_{2} \mathrm{~N}\right]\right)$ is at about $400{ }^{\circ} \mathrm{C}$ and silica adsorbents without IL content (SG-Ø) is started to decompose at low temperatures around $50{ }^{\circ} \mathrm{C}$. The adsorbents containing imidazolium based ionic liquid with the weight percentages of 20 and $40 \%$, show increase in $\mathrm{T}_{\mathrm{d}}$ compared to pure silica adsorbents (SG-Ø). It can be concluded that, thermal stability of prepared adsorbents increased upon confinement of ILs.

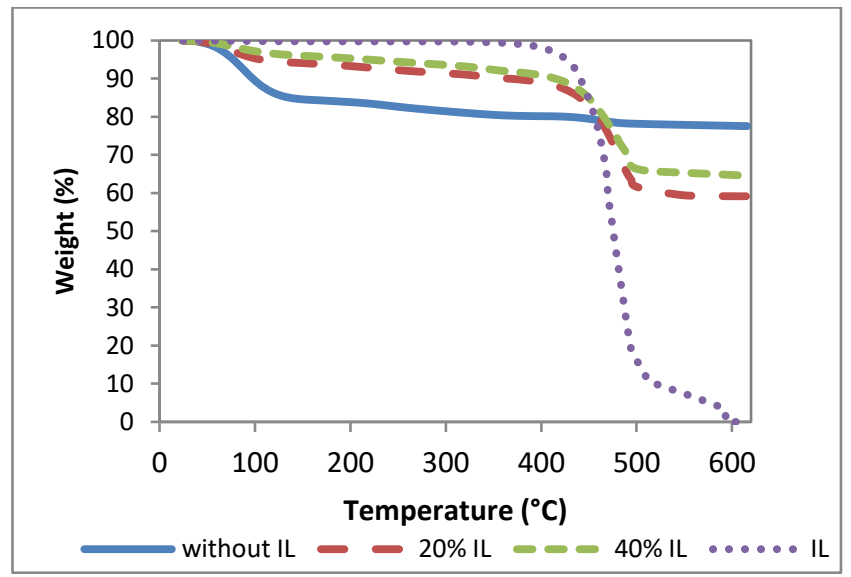

Figure 4. TGA thermograms of SG-IL adsorbents.

\subsection{Effect of IL type on the sorption of $\operatorname{Cr}(V I)$ ions}

Sorption performances of silica based adsorbents containing various amount and type of ionic liquid 
were evaluated as the removal percentage of $\mathrm{Cr}(\mathrm{VI})$ ions from aqueous solution. Effects of ionic liquid amount were also examined by using two different ratio of ILs on the mass basis such as 0.5 and $0.7 \mathrm{~g}$ IL/g-silica precursor. Results are shown in Figure 5.

It can be confirmed from Figure 5 that SG-TS and SG-A type adsorbents showed a better removal performance for $\mathrm{Cr}(\mathrm{VI})$ in comparison to untreated silica adsorbent (SG-Ø). Although the results of SG-A and SG-TS exhibited quiet similar results, SG- A can be chosen as adsorbent for the further studies. Because of the fact that SG-TS needs additional step for synthesis of ionic liquid comparing with the preparation of SG-A .

Sorption percentages of the adsorbents have been enhanced by containing Aliquat $336^{\circledR}$ type ionic liquids (SG-A) up to $99 \%$.

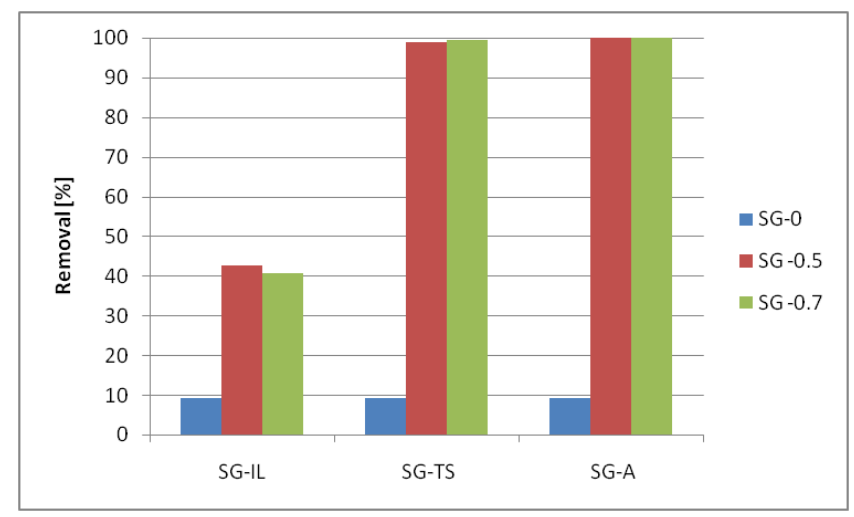

Figure 5. Removal efficiency of silica based adsorbents synthesized by using various type of ionic liquids for the sorption of $\mathrm{Cr}(\mathrm{VI})$ ions.
Adsorption capacity of SG-A type adsorbents was calculated as $31.74 \mathrm{mg} / \mathrm{g}$ and it is also observed that increase in IL content has no pronounced effect on the sorption performances.

The adsorption capacity of ionic liquid (Aliquat $336^{\circledR}$ ) incorporated into sol-gel silica adsorbent (SG-A) is compared with the capacity of the novel materials synthesized in the other studies as shown in Table 3.

Table 3. Comparison of $\mathrm{Cr}(\mathrm{VI})$ adsorption capacities of different adsorbents reported in literature

\begin{tabular}{|lcc|}
\hline Adsorbent & Capacity (mg/g) & References \\
\hline Maghemite nanoparticles with polyrhodanine & $13.51-25.85$ & 28 \\
Nanoporous activated neem bark & 21.28 & 30 \\
Carbon/AlOOH composite & 25.64 & 31 \\
p(AN-co-APTMACl) hydrogel & 18.16 & 32 \\
Hybrid cellulose aerogel (ZIF@CA) & 41.80 & 33 \\
Expanded graphite/layered double hydroxides (EG/LDHs) & 13.44 & 34 \\
nanocomposites & 35.00 & 35 \\
Mgnetic titanium nanotubes coated phosphorene (MNP-PN-TNT) & 31.74 \\
Ionic iquid (Aliquat 336) incorporated sol-gel silica (SG-A) & & Present \\
\end{tabular}

As indicated in Table 3., SG-A adsorbent exhibits adsorbent incorporated with ionic liquid is a very higher adsorption capacity than most of the promising material for the removal of Cr(VI) ions. adsorbents previously reported in literature. Therefore, It can be concluded that the silica based 


\section{Conclusion}

In this study ionic liquid mediated sol-gel silica adsorbents are prepared for the removal of Cr (VI) ions from aqueous solutions. Physicochemical and morphological characterization of prepared adsorbents concluded that ionic liquids acted as porogens and increased the thermal stability of the silica based adsorbents.

Based upon the experimental results, $\mathrm{Cr}(\mathrm{VI})$ sorption percentages achieved with silica adsorbents containing ionic liquid were higher than that of untreated adsorbents due to synergistic effect of electrostatic interaction with IL and $\mathrm{Cr}(\mathrm{VI})$ ions. Sorption percentages of the adsorbents were enhanced by containing ILs up to $99 \%$ with the adsorption capacity of $31.74 \mathrm{mg} / \mathrm{g}$. It can be concluded that sorption of $\mathrm{Cr}(\mathrm{VI})$ ions from aqueous solution by solgel silica based adsorbents containing Aliquat $336^{\circ}$ takes place favorably and these type of adsorbents are very prospective materials for the adsorption of $\mathrm{Cr}$ (VI) from aqueous streams.

\section{Acknowledgement}

The authors are grateful to Ege University Research Foundation (contract no: 17MÜH042) and The Scientific and Technological Research Council of Turkey (TUBITAK) for financial supports under Contract No: 213M537 and.

\section{Conflicts of interest}

The authors state that did not have conflict of interests

\section{References}

[1] Liu Y., Guo L., Zhu L., Sun X., Chen J., Removal of Cr (VI) by quaternary ammonium and quaternary phosphonium ionic liquids functionalized silica materials, Chem. Eng. J. 158, (2010) 108-114.

[2] World Health Organisation (WHO) sensate, Available at http://www.who.int/water_sanitation_health/dwq /chemicals/chromium.pdf. Retrieved at 15 October (2017).

[3] Lin X., Liu J., Wan S., He X., Cui L., Wu G. A novel strategy for $\mathrm{Cr}$ (VI) removal from aqueous solution via CYPH@ IL101/chitosan capsule, Int. J. Biol. Macromol., 136 (2019) 35-47.
[4] Rawat A. P., Sing D. P. Synergistic action of adsorption and reductive properties of ash derived from distilled Mentha piperita plant waste in removal of $\mathrm{Cr}(\mathrm{VI})$ from aqueous solution, Ecotoxicol. Environ. Saf., 176 (2019) 27-33.

[5] Zhou L., Duan Y., Xu X. Facile preparation of amine-rich polyamidoamine (PAMAM) gel for highly efficient removal of $\mathrm{Cr}(\mathrm{VI})$ ions, Colloids and Surfaces A, 579 (2019), 123685.

[6] Shakya A., Agarwal T. Removal of Cr(VI) from water using pineapple peel derived biochars: Adsorption potential and re-usability assessment, J. Mol. Liq., (2019) 111497.

[7] Sellami F., Kebiche-Senhadji O., Marais S., Couvrat N., Fatyeyeva K. Polymer inclusion membranes based on CTA/PBAT blend containing Aliquat 336 as extractant for removal of $\mathrm{Cr}(\mathrm{VI})$ : Efficiency, stability and selectivity, React. Funct. Polym., 139 (2019) 120-132.

[8] Benaissa H., Elouchdi M. A. Removal of copper ions from aqueous solutions by dried sunflower leaves, Chem. Eng. Process., 46 (2007) 614-622.

[9] Fu F., Wang Q. Removal of heavy metal ions from wastewaters: a review, J. Environ. Manage., 92 (2011) 407-418.

[10] Bilal M., Shah J. A., Ashfaq T., Gardazi S. S, Tahir A. A., Pervez A., Haroon H., Mahmood Q. J. Waste biomass adsorbents for copper removal from industrial waste water-a review, J. Hazard. Mater., 262(3) (2013) 322-333.

[11] Mahmoud M.E., Hafez O. F., Alrefaay A., Osman M. M. Performance evaluation of hybrid inorganic/organic adsorbents in removal and preconcentration of heavy metals from drinking and industrial waste water, Desalination, 253 (2010) 9-15.

[12] Tian Y., Yin P., Qu R., Wang C., Zheng H., Yu Z. Removal of transition metal ions from aqueous solution by adsorption using a novel hybrid material silica gel chemically modified by trithylenetetraminomethylenephosphonic acid, Chem. Eng. J., 162 (2010) 573-579.

[13] Gizli N., Arabac1 M., Enhanced sorption of $\mathrm{Cu}$ (II) ions from aqueous solution by ionic liquid impregnated nano-silica and nano-alumina particles, Chem. Ind. Chem. Eng. Q., 23(2) (2017) 207-216. 
[14] Peric B., Martí E., Sierra J., Cruañas R., Garau M.A., Recent Advances in Pharmaceutical Sciences II, Munoz-Torrero D., Haro D., Valles J., (Eds). Transworld Research Network. Kerela, India, (2012).

[15] Stojanovic A., Keppler B., Ionic liquids as extracting agents for heavy metals, Sep. Sci. Technol., 47 (2012) 183-203.

[16] Dong Z., Zhao L. Covalently bonded ionic liquid onto cellulose for fast adsorption and efficient separation of $\mathrm{Cr}(\mathrm{VI})$ : Batch, column and mechanism investigation, Carbohydr. Polym., 189 (2018), 190-197.

[17] Kim B-K., Lee E. J., Kang Y., Lee J-J. Application of ionic liquids for metal dissolution and extraction, J. Ind. Eng. Chem., 61 ( 2017) 388-397.

[18] Li Z. L., Lin G., Zhenjiang Z., Ji C., Min Z. S. The preparation of supported ionic liquids (SILs) and their applications in rare metal separation, Science China Chemistry, 55 (2012) 1479-1488.

[19] Lemus J., Palomar J., Gilarranz M. A., Rodriguez J. J. Characterization of Supported Ionic Liquid Phase (SILP) materials prepared from different supports, Adsorption, 17 (2011) 561-571.

[20] Hung W-C., Fu S-H., Tseng J-J, Chu H., Ko TH. Study on photocatalytic degradation of gaseous dichloromethane using pure and iron ion-doped $\mathrm{TiO} 2$ prepared by the sol-gel method, Chemosphere, 66 (2007) 2142-2151.

[21] Dai S., Ju Y. H., Gao H. J., Lin J. S., Pennycook S. J., Barnes C. E. Preparation of silica aerogel using ionic liquids as solvents, Chem Commun., 3 (2000) 243-244.

[22] Perchacz M., Donato R. K., Seixas L., Zhigunov A., Konefat R., Serkis-Rodzen M., Benes H. Ionic liquid-silica precursors via solvent-free sol-gel process and their application in epoxyamine network: a theoretical/experimental study, ACS Appl. Mater. Interfaces, 9 (2017) 16474-16487.

[23] Zhou Y., Schattka J. H., Antonietti M. Roomtemperature ionic liquids as template to monolithic mesoporous silica with wormlike pores via a sol-gel nanocasting technique, Nano Letters, 4(3) (2002), 477-481.

[24] Viau L.,Neouze M-A., Biolley C., Volland S., Brevet D., Gaveau P., Dieudonne P., Galarneau A., Vioux A. Ionic liquid mediated sol-gel synthesis in the presence of water or formic acid: which synthesis for which material?, Chem. Mater., 24 (2012), 3128-3134.

[25] Klingshirn, M.A., Spear, S.K., Holbrey, J.D., Rogers, R.D. Ionic liquids as solvent and solvent additives for the synthesis of sol-gel materials, $J$. Mater. Chem., 15 (2005) 5174-5180.

[26] Karout A., Pierre A. C., Silica xerogels and aerogels synthesized with ionic liquids, J. NonCryst. Solids, 353 (2007) 2900-2909.

[27] Zhang J., Maa Y., Shi F., Liu L., Deng Y. Room temperature ionic liquids as templates in the synthesis of mesoporous silica via a sol-gel method, Microporous and Mesoporous Materials, 119 (2009), 97-103.

[28] Ekka B., Rout L., Kumar M. K. S. A., Patel R. K., Dash P. Removal efficiency of Pb (II) from aqueous solution by 1-alkyl-3methylimidazolium bromide ionic liquid mediated mesoporous silica,_J. Environ. Chem. Eng., 3(2) (2015), 356-1364.

[29] Seraj S., Mirzayi B., Nematollahzadeh A. Engineered maghemite nanoparticles with polyrhodanine for efficient removal of $\mathrm{Cr}(\mathrm{VI})$ from water, Environmental Nanotechnology, Monitoring \& Management, 10 (2019), 94-103.

[30] Maheshwari U., Mathesan B., Gupta S. Efficient adsorbent for simultaneous removal of $\mathrm{Cu}$ (II), $\mathrm{Zn}(\mathrm{II})$ and $\mathrm{Cr}(\mathrm{VI})$ : Kinetic, thermodynamics and mass transfer mechanism, Process Saf. Environ. Prot., 98 (2015), 198-210.

[31] Kumar R., Ehsan M., Barakat M. A. Syhthesis and characterization of carbon/AlOOH composite for adsorption of chromium (VI) from synthetic wastewater, J. Ind. Eng. Chem., 20(6) (2014) 4202-4206.

[32] Dudu T.E., Sainer M., Alpaslan D., Demirci S. Removal of $\mathrm{As}(\mathrm{V}), \mathrm{Cr}(\mathrm{III})$ and $\mathrm{Cr}(\mathrm{VI})$ from aqueous environments by poly(acrilonitril-coacrylamidopropyl-trimethyl ammonium chloride) based hydrogels, J. Environ. Manage., 161 (2015) 243-251.

[33] Bo S., Ren W., Lei C., Xie Y., Cai Y., Wang S., Gao J., Ni Q., Yao J. Flexible and porous cellulose aerogels/zeolitic imidazolate framework (ZIF-8) hybrids for adsorption removal of $\mathrm{Cr}(\mathrm{VI})$ from water, J. Solid State Chem., 262 (2018) 135-141.

[34] Hu Z., Cai L., Liang J., Guo X., Li W., Huang Z. Green synthesis of expanded graphite/layered double hydroxides nanocomposites and their 
application in adsorption removal of $\mathrm{Cr}(\mathrm{VI})$ from aqueous solution, J. Clean. Prod.,209 (2019) 1216-1227.

[35] Lin Y.-J., Chen J.-J., Cao W.-Z., Persson K. M., Ouyang T., Zhang L., Xie X., Liu F., Li J., Chang C.-T. Novel materials for $\mathrm{Cr}(\mathrm{VI})$ adsorption bu magnetic titanium nanotubes coated phosphorene, J. Molec. Liq.,287 (2019) 110826. 